\title{
Alagille Syndrome
}

National Cancer Institute

\section{Source}

National Cancer Institute. Alagille Syndrome. NCI Thesaurus. Code C35139.

An autosomal dominant genetic syndrome caused by mutations in the JAG1 gene. It is characterized by cholestatic jaundice in infancy, hepatosplenomegaly, distinctive facial features (prominent forehead, elong ated nose, and pointed chin), cardiac murmurs, bone malformations, and sometimes mild mental retardation. 